\title{
Variation of the Impact Aroma Compound, 2-Acetyl-1-Pyrroline, Content in Thai Fragrant Rice Plants and its Enhanced Accumulation by Soil Nutritional Elements
}

\author{
Wichwara Nawara ${ }^{1}$, Chonlada Bennett ${ }^{1}$, Orranuch Norkaew ${ }^{1}$, Phumon Sookwong ${ }^{1,2}$, Sakul Moolkam ${ }^{3}$, \\ Sivapong Naruebal $^{4} \&$ Sugunya Mahatheeranont ${ }^{1,2,5}$ \\ ${ }^{1}$ Department of Chemistry, Faculty of Science, Chiang Mai University, Chiang Mai, Thailand \\ ${ }^{2}$ Research Center on Chemistry for Development of Health Promoting Products from Northern Resources, Chiang \\ Mai University, Chiang Mai, Thailand \\ ${ }^{3}$ Rice Department, Chiang Mai Rice Research Centre, Sanpatong, Chiang Mai, Thailand \\ ${ }^{4}$ Rice Department, Mae Hong Son Rice Research Centre, Pang Mapha, Mae Hong Son, Thailand \\ ${ }^{5}$ Center of Excellence for Innovation in Chemistry, Faculty of Science, Chiang Mai University, Chiang Mai, \\ Thailand
}

Correspondence: Sugunya Mahatheeranont, Department of Chemistry, Faculty of Science, Chiang Mai University, Chiang Mai, 50200, Thailand. E-mail: sugunya.w@gmail.com

Received: March 3, 2020

doi:10.5539/jas.v12n6p36
Accepted: April 6, $2020 \quad$ Online Published: May 15, 2020

URL: https://doi.org/10.5539/jas.v12n6p36

\begin{abstract}
This study investigated the accumulation characteristics of 2-acetyl-1-pyrroline (2AP) in the Thai Jasmine rice cultivar, Khao Dawk Mali 105 (KDML 105) under different soil types and addition of soil nutritional elements. There was significant variation in the 2AP contents of rice leaves, not only among different growth stages, but also among different leaf positions at each growth stage. The highest 2AP content was seen in the third leaves at booting stage $\left(25.10 \pm 0.90 \mu \mathrm{g} \mathrm{g}^{-1}\right)$, whilst for flag leaves it was seen at mature grain stage $\left(8.00 \pm 0.72 \mu \mathrm{g} \mathrm{g}^{-1}\right)$. During the ripening stage, plants in sandy soil acquired higher 2AP content in flag leaves, spikelets, and seeds than in clay soil, with the highest $2 \mathrm{AP}$ content in flag leaves at $25.00 \pm 0.70 \mu \mathrm{g} \mathrm{g}^{-1}$. The accumulation of $2 \mathrm{AP}$ in basal, middle, and upper branches of panicles showed no significant differences, whereas a steady decrease in $2 \mathrm{AP}$ content was detected in the panicle axis and branches. The effects of individual mineral elements $(\mathrm{B}, \mathrm{Cr}, \mathrm{Cu}, \mathrm{Mg}$, $\mathrm{Mn}$, and Se) on 2AP content was different at each growth stage. B enhanced the 2AP content by more than two-fold in the leaves at the heading stage $\left(63.84 \pm 4.56 \mu \mathrm{g} \mathrm{g}^{-1}\right)$ compared to that of the control set, followed by Mn, $\mathrm{Cu}$, and Se. Similar to the above results, the $2 \mathrm{AP}$ content was also heightened in grains. The extended knowledge gathered in this study will assist farmers who wish to improve the fragrance qualities of their rice varieties.
\end{abstract}

Keywords: 2-acetyl-1-pyrroline, boron, copper, fragrant rice, mineral elements, selenium, static headspace-gas chromatography

\section{Introduction}

Mineral elements in soil are known to have physiological functions in plants, acting as enzymatic activators, osmotic regulators, electron transporters, or constituents of organic/inorganic compounds (Hänsch \& Mendel, 2009; Xie et al., 2004). However, the effect of mineral nutrients, other than $\mathrm{Na}$ and $\mathrm{Cl}$, on rice plants, especially the effects on 2-Acetyl-1-pyrroline (2AP) content have not been widely investigated. The majority of research has focused on the effects of mineral elements on rice plant morphology and grain quality (Zeng et al., 2005), but little research has focused on the 2AP content in rice plant parts and grain.

Aroma compound 2AP is found in many plant species and is credited as one of the most important traits of aromatic rice. Thai jasmine rice variety, Khao Dawk Mali 105 (KDML 105), is a non-glutinous, fragrant rice variety, famous for its eating and cooking quality due to its high 2AP content. Multiple studies have been conducted on the gene responsible for 2AP in rice plants and research on environmental differences such as soil type, salinity, and water stress, have all been linked to the accumulation of 2AP in rice grains (Sarvestani, Pirdashti, Sanavy, \& Balouchi, 2008; Thanachit, Jedrum, Anusontpor, \& Wiriyakitn, 2014; Boontakham, Sookwong, 
Jongkaewwattana, Wangtueai, \& Mahatheeranont, 2019). According to these reports, drought conditions and sandy soils are favourable for 2AP accumulation, although the predominant rice cultivation conditions are usually flooded clay soils (R. Singh, U. Singh, \& Khush, 2000). Water stress treatment of KDML 105 after heading increases the amount of $2 \mathrm{AP}$ by $18 \%$ in leaves and $22 \%$ in grains (Boontakham et al., 2019). Another report described the correlation between 22 different locations possessing eight different soil textures in the northeastern part of Thailand and the 2AP content of KDML 105 rice grains. Sandy soil conditions and soil pH of 5.27 showed the highest 2AP content (Kong-ngern et al., 2011). The sandy soil texture is closely linked to water stress environments as the capacity for water retention is lower in sandy soils than that of clay soils. The effect of ripening is affected by temperature and geographical locations (Ishimaru et al., 2018; Pitiphunpong \& Suwannaporn, 2009) and significantly affect 2AP content in grains and yield in rice plants. Saline conditions have also been extensively studied (Funsueb, Krongchai, Mahatheeranont, \& Kittiwachana, 2016; Gay et al., 2010; Lutts, Kinet, \& Bouharmont, 1996). In most reports, it is concluded that saline soil conditions increase the 2AP content in rice grains and improves the grain yield of aromatic rice at harvest. Furthermore, the effects of minerals, such as $\mathrm{Zn}, \mathrm{Fe}$, and La have been studied on the aroma content of brown rice and the proline content in leaves and panicles (Tang \& Wu, 2006; Xiao et al., 2010; Mo et al., 2016). Zn and La promote higher 2AP concentrations in the rice panicles and grains due to increased proline concentrations and proline dehydrogenase activities. It can be hypothesised that the increase in aroma content of rice leaves at cultivation could increase the aroma content of rice grains.

The aim of this research was to enhance 2AP content in leaves and seeds of KDML 105 Thai rice. This was achieved by investigating the 2AP content in plants at different developmental stages, grown under different cultivation conditions, including different soil conditions and mineral element treatments. The 2AP content in rice seeds and leaves grown in sandy and clay soil were compared. The accumulation of 2AP in rice leaves at different leaf positions and panicle branches of rice plants was determined to observe the characteristics of 2AP accumulation. Moreover, the influence of nutritional elements commonly available in soil, such as $\mathrm{Mg}, \mathrm{B}, \mathrm{Mn}$, $\mathrm{Cu}, \mathrm{Cr}, \mathrm{Se}$, on the growth and variation in $2 \mathrm{AP}$ content in leaves and seeds was studied. These results will help to clarify the translocation characteristic of $2 \mathrm{AP}$ content in rice plants and expand the understanding of the true nature behind the development of 2AP in rice plants and environmental factors that influence the accumulation of 2AP. The extended knowledge gathered will be of assistance to farmers around the world who wish to improve the fragrant qualities of their rice varieties.

\section{Materials and Methods}

\subsection{Chemicals}

The standard compound 2AP was synthesized following two steps: hydrogenation and oxidation. In the first step, 2 -acetylpyrrole was hydrogenated using $5 \%$ rhodium on activated alumina as the catalyst. After the maximum amount of the hydrogenation product had been obtained, the rhodium catalyst was removed and solvent was evaporated to give 2-(1-hydroxyethyl)pyrrolidine, a pale yellow viscous product. The oxidation reaction in the second step employed silver carbonate on Celite as a catalyst. The purified 2AP was yielded after separation on a packed column of a gas chromatograph and collected in a 3-mm o.d. Pyrex tube. This tube was then sealed under an $\mathrm{N}_{2}$ atmosphere and kept at $-20^{\circ} \mathrm{C}$. The purity and chemical structure of the synthetic $2 \mathrm{AP}$ were confirmed by gas chromatography-mass spectrometry (GC-MS) and nuclear magnetic resonance spectroscopy (NMR). The compound 2,6-dimethylpyridine (2,6-DMP) was used as internal standard. The basic fertilizer consisted of ammonium nitrate, potassium nitrate, and potassium dihydrogen orthophosphate. The individual mineral element included B (as B-amino acid complex), Se (as L-selenomethionine), Mn (as Mn amino acid chelate), $\mathrm{Cu}$ (as $\mathrm{Cu}$ amino acid chelate), $\mathrm{Cr}$ (as $\mathrm{Cr}$ amino acid chelate) and $\mathrm{Mg}$ (equivalent to $\mathrm{Mg}(\mathrm{OH})_{2}$ ).

\subsection{Cultivation Conditions}

The non-glutinous, fragrant rice cultivar KDML 105 was grown at the experimental field of Chiang Mai Rice Research Centre, Sanpatong, Chiang Mai, Thailand. The growth period was from August to early December 2017 and 2018, with the average daily temperature ranging from $19{ }^{\circ} \mathrm{C}$ to $32{ }^{\circ} \mathrm{C}$. KDML 105 rice seeds were soaked and kept in the dark for $24 \mathrm{~h}$ for germination and nursed in soil trays for two weeks before being transported to growing pots and experimental fields. Sampling was carried out at the same time of day $(9-10 \mathrm{am})$ and the samples were stored at $-20^{\circ} \mathrm{C}$ one day before analysis.

\subsubsection{Cultivation of KDML 105 Rice in Sandy Soil for Collection of Leaves and Panicles at Different Positions}

Rice seedlings were transported to the experimental field (40 $\mathrm{m} \times 20 \mathrm{~m}$; in length and width respectively) and grown in sandy soil. Leaves were collected at random from various locations in the field during nine developmental stages including seedling, tillering, panicle initiation, booting, heading, milk grain, soft dough 
grain, hard dough grain, and mature grain. Panicles were carefully collected at booting, heading, milk grain, soft grain, hard dough, and mature grain stages. To investigate the variation in 2AP content in different leaf positions, samples were collected at the flag leaf (uppermost leaf below the panicle) and the second and third leaf position of rice plants. The primary panicles at flag leaf position were collected and the seeds of the panicle were separated evenly as the basal, middle and upper branches, and the panicle axis were analysed independently from the seeds. The characteristics of 2AP from leaves to grain was thus determined.

\subsubsection{Cultivation of KDML 105 Rice in Different Soil Types}

Rice seedlings were transplanted into 10-inch experimental plant pots $(n=3)$ filled with clay or sandy soil. Rice flag leaves and panicles were collected at heading, milk grain, soft dough grain, hard dough grain, and mature grain stages. The comparison of growth in sandy and clay soil was carried out to clarify research already established by other authors. The characteristics of 2AP from leaves to grains was also clarified in these experiments.

\subsubsection{Cultivation of KDML105 Rice With Addition of Mineral Elements}

To obtain the appropriate concentration of mineral elements, a preliminary study on KDML 105 plant developmental growth with the application of different concentrations of ten mineral elements was carried out. The mineral elements used were $\mathrm{Ca}, \mathrm{Mg}, \mathrm{B}, \mathrm{Zn}, \mathrm{Mn}, \mathrm{Cu}, \mathrm{Mo}, \mathrm{Fe}, \mathrm{Cr}$, and Se. Four concentrations of individual elements were prepared following the minimum and maximum range reported in the literature (Schwarz, 1995). Rice seedlings were transplanted into 10-inch plant pots $(\mathrm{n}=3)$ filled with clean sand and placed into a larger 12-inch pot filled with nutrient solution. The plants were supplied with a basic fertiliser solution (nitrogen (N), phosphorus (P), Potassium (K)), prepared by modifying the solution of Hoagland and Arnon (Jones, 2014). Individual elements were supplied along with NPK basic fertiliser solution twice a week over a period of 12 weeks. The experiment was conducted in open-air conditions with natural sunlight at the experimental field of the Chiang Mai Rice Research Center, Sanpatong.

From the preliminary experiment, six mineral elements applied at their most appropriate concentrations (Table 1) to obtain the largest grain yield and growth were selected for the investigation of individual mineral elements. Rice plants were transplanted into 10 and 12 -inch plant pots $(\mathrm{n}=3)$ containing sand and nutrient solution. Basic fertiliser NPK were supplied with individual elements twice a week for 12 weeks. Rice leaves and seeds were collected at four developmental stages for the quantification of $2 \mathrm{AP}$ content.

Table 1. Concentration of Mineral elements added to potted soil

\begin{tabular}{ll}
\hline Mineral Element & Concentration $(\mathrm{ppm})$ \\
\hline Magnesium & 100.00 \\
Copper & 1.00 \\
Chromium & 3.37 \\
Selenium & 0.10 \\
Boron & 1.03 \\
Manganese & 2.50 \\
\hline
\end{tabular}

\subsection{Quantification of 2-Acetyl-1-Pyrroline in Leaves and Seeds of KDML 105 Rice}

Rice samples were dried under ambient conditions to reach a moisture content of approximately $14 \%$. Leaf samples $(0.20 \mathrm{~g})$ were ground with a blender (Y46; Moulinex, Paris, France) and placed into $20 \mathrm{~mL}$ headspace vials with $1.0 \mu \mathrm{l}$ of $500 \mathrm{ppm}$ and 2,6-DMP added as an internal standard. The headspace vials were sealed immediately with polytetrafluoroethylene silicone (PTFE/silicone) septa and aluminum caps prior to analysis by static headspace-gas chromatography coupled with a nitrogen/phosphorus detector (SHS-GC-NPD).

Quantification of 2AP in samples was performed according to the method of Boontakham et al. (2019). A static headspace auto-sampler (Model G1888, Agilent Technologies, CA, USA) coupled to an Agilent 6890 Series GC system equipped with an NPD detector was used. The optimum headspace operating conditions were: oven temperature $120^{\circ} \mathrm{C}$; loop temperature $130{ }^{\circ} \mathrm{C}$; transfer line temperature $140{ }^{\circ} \mathrm{C}$; vial equilibration time 5 min with high speed shaking; pressurising time $0.05 \mathrm{~min}$; loop filling time $0.6 \mathrm{~s}$; loop equilibration time $24 \mathrm{~s}$; and injection time $24 \mathrm{~s}$. 
Separation of headspace volatiles was done using an HP-5 $(30 \mathrm{~m} \times 0.53 \mathrm{~mm}$ i.d. $\times 1.5 \mu \mathrm{m}$ film thickness $)$ column (J\&W Scientific, Folsom, CA, USA). The column temperature was programmed to initiate at $50{ }^{\circ} \mathrm{C}$ and was increased to $125^{\circ} \mathrm{C}$ at a gradient of $8{ }^{\circ} \mathrm{C} \mathrm{min}^{-1}$. Purified helium was used as $\mathrm{GC}$ carrier gas at a flow rate of 5 $\mathrm{mL} \min ^{-1}$. The NPD temperature was set at $300^{\circ} \mathrm{C}$.

A calibration curve for $2 \mathrm{AP}$ content in rice leaves was made by diluting the $2 \mathrm{AP}$ standard solution with toluene to yield a $0.5-50.0 \mu \mathrm{g} \mathrm{mL}^{-1}$ concentration series, which was added to headspace vials containing $0.20 \mathrm{~g}$ of non-aromatic rice leaves (Suphanburi 2), used as the solid phase material. The internal standard, $1 \mu \mathrm{L}$ of $0.50 \mathrm{mg}$ $\mathrm{mL}^{-1}$ 2,6-DMP in toluene, was added to each vial and the vials were immediately sealed with PTFE/silicone septa and aluminum caps prior to analysis by the SHS-GC-NPD.

\subsection{Statistical Analysis}

Each experiment was carried out in triplicate and results were expressed as the mean \pm SD. Statistical differences among treatments were calculated by one-way analysis of variance (ANOVA) using SPSS software, version 17.0 (SPSS Inc., Chicago, IL). Significant differences were assessed by post hoc Tukey test with the level of significance set at $95 \%(\mathrm{P}<0.05)$.

\section{Results}

\subsection{Variation of $2 A P$ Content at Nine Developmental Growth Stages}

The 2AP content in the leaves and panicles of KDML 105 rice during nine developmental stages are shown in Figure 1. The 2AP content of fresh rice leaves at seedling stage was $6.31 \pm 0.045 \mu \mathrm{g} \mathrm{g}^{-1}$ and increased significantly during the development of leaves at active tillering $\left(10.28 \pm 0.82 \mu \mathrm{g} \mathrm{g}^{-1}\right)$ and panicle initiation stages $\left(12.92 \pm 0.81 \mu \mathrm{g} \mathrm{g}^{-1}\right)$. Among the three types of rice leaves at booting, the third leaf had the highest percentage of 2AP $\left(25.10 \pm 0.90 \mu \mathrm{g} \mathrm{g}^{-1}, 49.73 \%\right)$ followed by the second $\left(16.67 \pm 0.30 \mu \mathrm{g} \mathrm{g}^{-1}, 33.55 \%\right)$ and then the flag leaves $\left(8.44 \pm 0.51 \mu \mathrm{g} \mathrm{g}^{-1}, 16.72 \%\right)$. At booting, the panicles enclosed inside the leaf sheath already contained $4.89 \pm 0.80$ $\mu \mathrm{g} \mathrm{g}^{-1}$ of $2 \mathrm{AP}$.

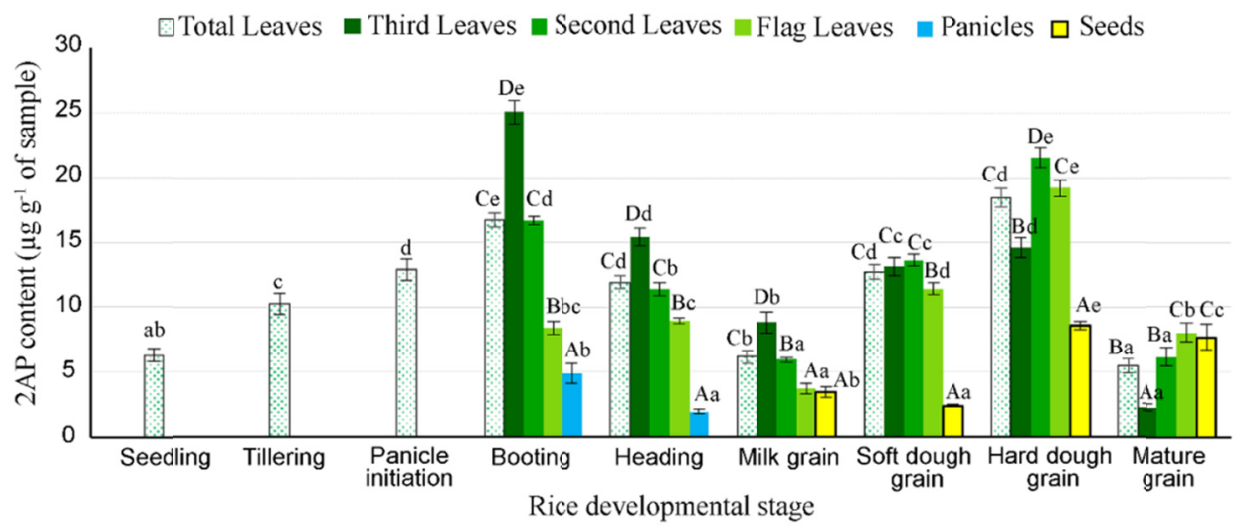

Figure 1. The 2AP contents in leaves and panicles of KDML 105 rice grown in sandy soil conditions during nine developmental stages

Note. Error bars represent standard deviation of sample $(\mathrm{n}=3)$. Significant differences $(\mathrm{P}<0.05)$ within the same column in the different growth stages are represent by lowercase letters and different column in the same growth stage by uppercase letters.

At heading stage, a reduction in $2 \mathrm{AP}$ content was observed in the third $\left(15.42 \pm 0.68 \mu \mathrm{g} \mathrm{g}^{-1}, 42.98 \%\right)$ and the second leaves $\left(11.47 \pm 0.50 \mu \mathrm{g} \mathrm{g}^{-1}, 31.96 \%\right)$. However, the $2 \mathrm{AP}$ content in flag leaves $\left(8.99 \pm 0.22 \mu \mathrm{g} \mathrm{g}^{-1}, 25.06 \%\right)$ at the heading stage increased slightly from booting. The $2 \mathrm{AP}$ content in the panicle at heading $\left(1.92 \pm 0.18 \mu \mathrm{g} \mathrm{g}^{-1}\right)$ was significantly lower than that at booting $\left(3.47 \pm 0.42 \mu \mathrm{g} \mathrm{g}^{-1}\right)$.

All leaf types showed a significant decrease in $2 \mathrm{AP}$ content at the milk grain stage. The third leaves $(10.34 \pm 0.80$ $\left.\mu \mathrm{g} \mathrm{g}^{-1}\right)$ had the highest amount of 2AP followed by second $\left(5.96 \pm 0.18 \mu \mathrm{g} \mathrm{g}^{-1}\right)$ and flag leaves $\left(3.69 \pm 0.40 \mu \mathrm{g} \mathrm{g}^{-1}\right)$. At soft dough grain stage, the 2AP content in rice leaves was significantly higher than that at the milk grain stage. The second leaves had a higher percentage of $2 \mathrm{AP}\left(13.64 \pm 0.46 \mu \mathrm{g} \mathrm{g}^{-1}, 35.65 \%\right)$ than that of the third and flag leaves $\left(13.15 \pm 0.67 \mu \mathrm{g} \mathrm{g}^{-1}, 34.36 \%\right.$ and $11.47 \pm 0.50 \mu \mathrm{g} \mathrm{g}^{-1}, 29.98 \%$, respectively). 
The hard dough grain stage showed the second $\left(21.58 \pm 0.76 \mu \mathrm{g} \mathrm{g}^{-1}, 38.98 \%\right)$ and flag leaves $\left(19.19 \pm 0.63 \mu \mathrm{g} \mathrm{g}^{-1}\right.$, $34.67 \%)$ to have a significantly higher $2 \mathrm{AP}$ contents than that of the third leaves $\left(14.59 \pm 0.77 \mu \mathrm{g} \mathrm{g}^{-1}, 26.36 \%\right)$. This trend continued through to the mature grain stage. At the mature grain stage, the 2AP content of seeds was $7.65 \pm 0.99 \mu \mathrm{g} \mathrm{g}^{-1}$ and did not differ significantly from that of the second and flag leaves. At this stage, the highest percentage of $2 \mathrm{AP}$ was found in flag leaves $\left(8.00 \pm 0.72 \mu \mathrm{g} \mathrm{g}^{-1}, 48.62 \%\right)$, followed by the second $(6.16 \pm 0.66 \mu \mathrm{g}$ $\left.\mathrm{g}^{-1}, 37.43 \%\right)$, and the third leaves $\left(2.29 \pm 0.29 \mu \mathrm{g} \mathrm{g}^{-1}, 13.94 \%\right)$. This order is reversed with that of the booting stage.

The 2AP content in seeds at different branch positions and panicle axis of KDML 105 rice in five developmental stages are shown in Figure 2. The seeds from different branch positions and panicle axis showed no significant differences in 2AP content at the heading stage (1.92-2.29 $\left.\mathrm{g} \mathrm{g} \mathrm{g}^{-1}\right)$. During the milk grain stage, the 2AP content of the panicle axis $\left(4.51 \pm 0.45 \mu \mathrm{g} \mathrm{g}^{-1}\right)$ and seeds on the basal branches $\left(4.22 \pm 0.39 \mu \mathrm{g} \mathrm{g}^{-1}\right)$ were significantly higher than that of seeds on the middle $\left(3.03 \pm 3.46 \mu \mathrm{g} \mathrm{g}^{-1}\right)$ and the upper $\left(3.46 \pm 0.36 \mu \mathrm{g} \mathrm{g}^{-1}\right)$ branches. There was a steady decline in the 2AP content of the panicle axis after the milk grain stage. The amount of 2AP in seeds rose significantly at the hard dough grain stage, with $2 \mathrm{AP}$ content highest in the upper branches $(6.11 \pm 0.12 \mu \mathrm{g}$ $\left.\mathrm{g}^{-1}\right)$, followed by the basal $\left(5.58 \pm 0.20 \mu \mathrm{g} \mathrm{g}^{-1}\right)$, and the middle $\left(5.23 \pm 0.17 \mu \mathrm{g} \mathrm{g}^{-1}\right)$ branches. However, the $2 \mathrm{AP}$ contents in the panicle axis $\left(2.47 \pm 0.27 \mu \mathrm{g} \mathrm{g}^{-1}\right)$ was decreased. At the mature grain stage, the seeds at the upper $\left(7.19 \pm 0.28 \mu \mathrm{g} \mathrm{g}^{-1}\right)$ and the middle branches $\left(6.91 \pm 0.16 \mu \mathrm{g} \mathrm{g}{ }^{-1}\right)$ had higher 2AP contents than that of the basal branches $\left(6.47 \pm 0.13 \mu \mathrm{g} \mathrm{g}^{-1}\right)$, whilst the $2 \mathrm{AP}$ content in the panicle axis $\left(2.50 \pm 0.16 \mu \mathrm{g} \mathrm{g}^{-1}\right)$ remained the same.

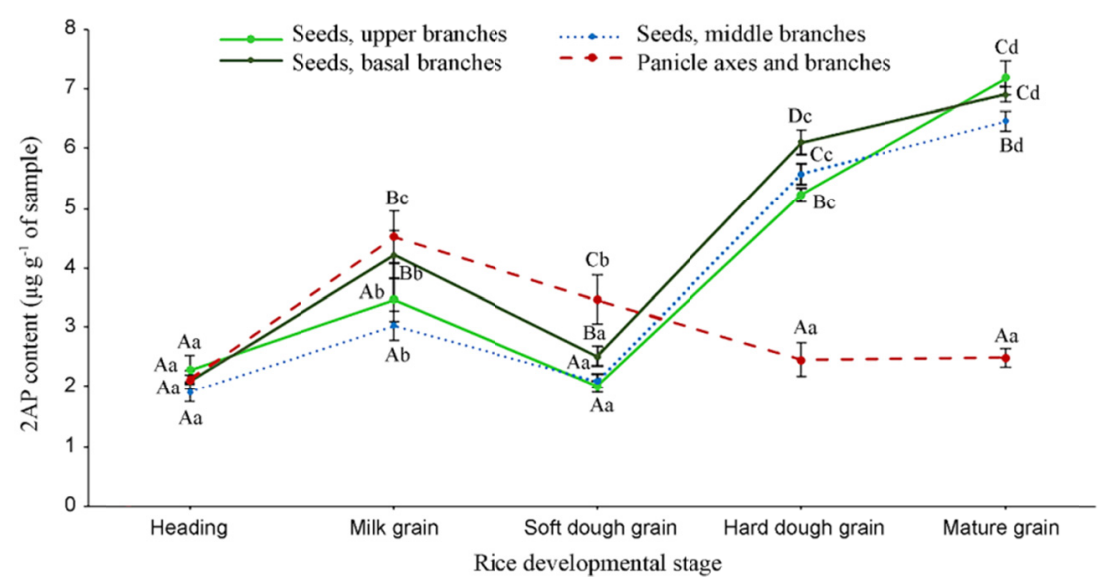

Figure 2. The $2 \mathrm{AP}$ contents in different parts of panicles, branches, and seeds at different branches of KDML 105 rice grown in sandy soil conditions during five developmental stages

Note. Error bars represent standard deviation of sample $(\mathrm{n}=3)$. Significant differences $(\mathrm{P}<0.05)$ within the same groups in the different growth stages are represent by lowercase letters and different groups in the same growth stages by uppercase letters.

\subsection{Variation of $2 A P$ Content in KDML 105 Rice in Response to Different Soil Types}

The effects of different soil types on 2AP content in flag leaves, spikelets, and seeds of KDML 105 rice grown with various soil types is shown in Figure 3. At the heading and milk grain stage, the 2AP concentration was significantly higher in flag leaves than that in spikelets or seeds, though no significant differences were observed between the two soils. However, at the soft dough grain stage, the 2AP content in flag leaves increased to $19.67 \pm 1.78 \mu \mathrm{g} \mathrm{g}^{-1}$ in sandy soil but increased only slightly to $9.67 \pm 0.93 \mu \mathrm{g} \mathrm{g}^{-1}$ in clay soil. The $2 \mathrm{AP}$ content in both sandy $\left(25.00 \pm 0.70 \mu \mathrm{g} \mathrm{g}^{-1}\right)$ and clay soil $\left(17.40 \pm 1.35 \mu \mathrm{g} \mathrm{g}^{-1}\right)$ continued to increase up to the hard dough stage with significant differences between them. The 2AP content in the flag leaves of mature grain decreased in both soil types, whereas in seeds, it increased. Ultimately, the seeds obtained from rice plants grown in sandy soil $\left(8.53 \pm 1.06 \mu \mathrm{g} \mathrm{g}^{-1}\right)$ showed significantly higher $2 \mathrm{AP}$ content $(\mathrm{p}<0.05)$ than that of seeds obtained from rice plants grown in clay soil $\left(5.00 \pm 0.96 \mu \mathrm{g} \mathrm{g}^{-1}\right)$. 


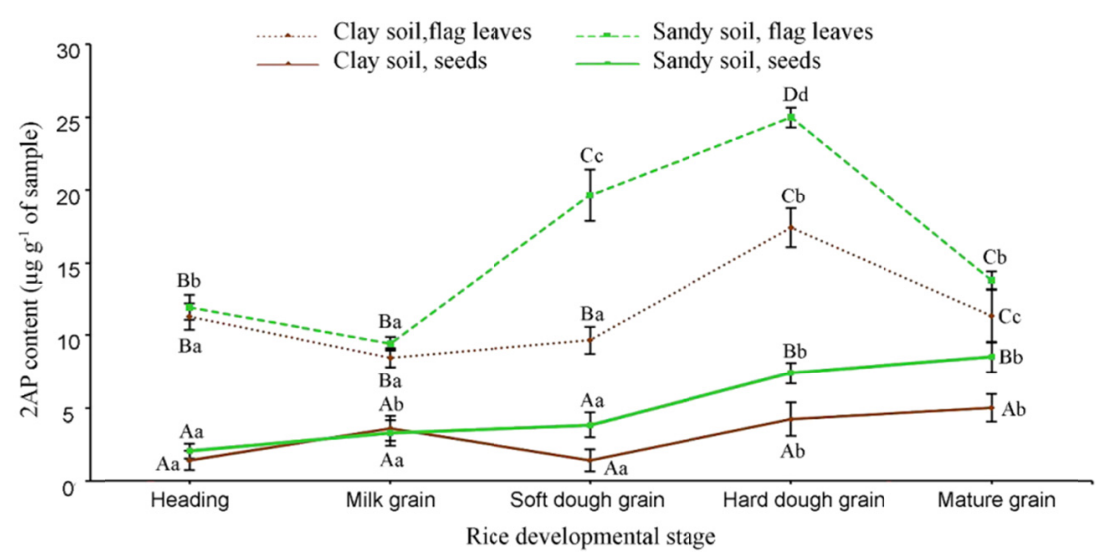

Figure 3. The effect of different soil types on 2AP content in spikelets, seeds, and flag leaves of KDML 105 rice during five developmental stages

Note. Error bars represent standard deviation of sample $(\mathrm{n}=3)$. Significant differences $(\mathrm{P}<0.05)$ within the same groups in different growth stages are represent by lowercase letters and different groups in the same growth stages by uppercase letters.

\subsection{Variation of $2 A P$ Content in KDML 105 Rice in Response to Addition of Mineral Elements}

The 2AP content in KDML 105 rice leaves at different developmental stages grown with the addition of nutritional elements are shown in Figure 4. At tillering, the highest $2 \mathrm{AP}$ content $\left(29.73 \pm 1.18 \mu \mathrm{g} \mathrm{g}{ }^{-1}\right)$ was observed in rice plants grown with the addition of Mg followed by Mn $\left(25.85 \pm 1.56 \mu \mathrm{g} \mathrm{g}^{-1}\right)$, and the control $\left(25.11 \pm 1.66 \mu \mathrm{g} \mathrm{g}^{-1}\right)$, with significant differences between the treatments $(\mathrm{p}<0.05)$. At the booting stage, the highest detectable amount of $2 \mathrm{AP}$ was observed in plants grown with the addition of $\mathrm{Cu}\left(49.33 \pm 0.65 \mu \mathrm{g} \mathrm{g}^{-1}\right)$, followed by $\mathrm{Cr}\left(41.71 \pm 1.97 \mu \mathrm{g} \mathrm{g}^{-1}\right)$, and $\mathrm{Mn}\left(35.07 \pm 0.52 \mu \mathrm{g} \mathrm{g}^{-1}\right)$, with significant differences between the treatments $(\mathrm{p}<0.05)$. At the heading stage, the highest $2 \mathrm{AP}$ content was observed in rice plants grown with the addition of B $\left(63.84 \pm 4.56 \mu \mathrm{g} \mathrm{g}^{-1}\right)$, followed by $\mathrm{Mn}\left(46.76 \pm 3.88 \mu \mathrm{g} \mathrm{g}^{-1}\right), \mathrm{Cu}\left(44.80 \pm 0.41 \mu \mathrm{g} \mathrm{g}^{-1}\right)$, and $\mathrm{Se}$ $\left(43.78 \pm 2.95 \mu \mathrm{g} \mathrm{g}^{-1}\right)$, the latter without significant difference $(\mathrm{p}<0.05)$. At the hard dough grain stage, the highest 2AP content was observed in leaves of control rice plants $\left(7.24 \pm 0.05 \mu \mathrm{g} \mathrm{g}^{-1}\right)$ followed by Se $\left(5.93 \pm 0.46 \mu \mathrm{g} \mathrm{g}^{-1}\right)$ and $\mathrm{Mn}\left(5.66 \pm 0.29 \mu \mathrm{g} \mathrm{g}^{-1}\right)$ with significant differences $(\mathrm{p}<0.05)$ between the treatments. In mature grain, the highest $2 \mathrm{AP}$ content in seeds was detected in B treated rice plants $\left(3.00 \pm 0.03 \mu \mathrm{g} \mathrm{g}^{-1}\right)$, followed by $\mathrm{Se}(2.61 \pm 0.02$ $\left.\mu \mathrm{g} \mathrm{g}^{-1}\right)$ with significant differences between the treatments $(\mathrm{p}<0.05)$.

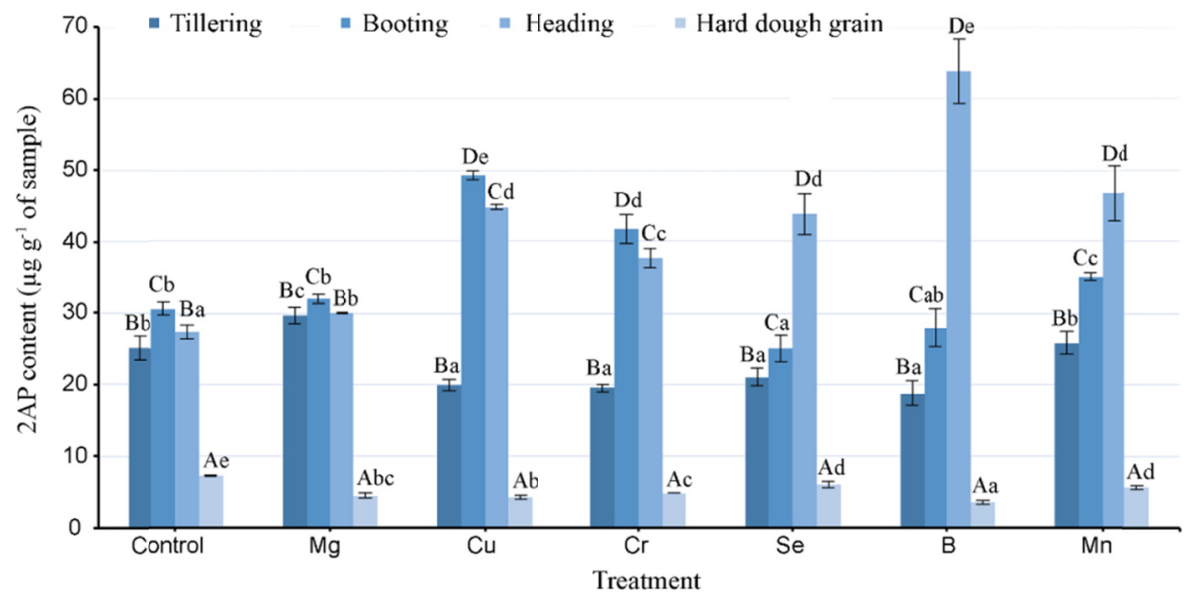

Figure 4. The 2AP contents of KDML 105 rice leaves at four developmental stages after treatment with different nutritional elements

Note. Error bars represent standard deviation of sample $(\mathrm{n}=3)$. Significant differences $(\mathrm{P}<0.05)$ within the same column in the same growth stages are represent by lowercase letters and different column in the same treatment by uppercase letters. 


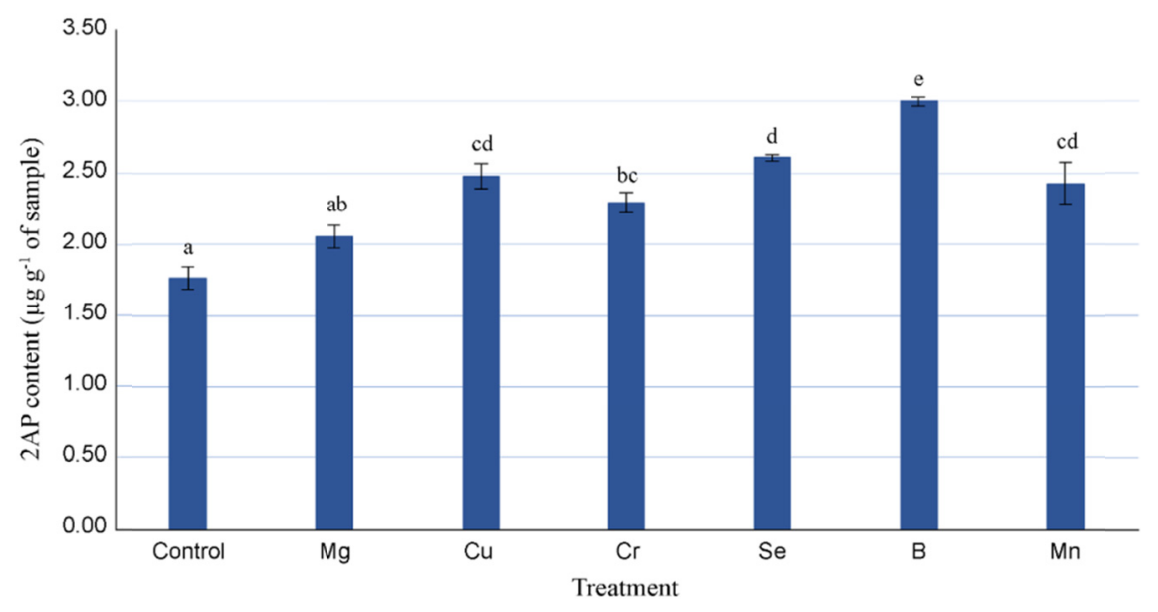

Figure 5. The 2AP contents of KDML 105 rice seeds at mature grain stage after treatment with different nutritional elements

Note. Error bars represent standard deviation of sample $(\mathrm{n}=3)$. Significant differences $(\mathrm{P}<0.05)$ are represent by lowercase letters.

\section{Discussion}

From rice seed germination, 2AP is synthesised in the leaves of aromatic rice at relatively high concentrations. The 2AP content in rice leaves increased until the booting stage, where the flag leaf fully emerges. At this stage, the $2 \mathrm{AP}$ content was seen to accumulate in the third leaves of rice plants but at the mature grain stage, the flag leaves had the highest 2AP content. The flag leaf provides not only an essential source of photosynthetic energy but also the nutritional and defensive metabolites necessary for panicle reproduction and grain filling processes. It thereby has a high impact on grain quality and yield.

The third leaves of rice plants from the booting to milk grain stage showed to have a significantly higher 2AP content than that of second and flag leaves. However, at the soft dough grain and hard dough grain stages, the 2AP content was higher in the second leaves than in the third and flag leaves. This showed that 2AP from the lower leaves at the base of rice plants was beginning to relocate towards the upper leaves in the top part of rice plants where grains developed.

The large decrease in the aroma compounds in rice leaves at the mature grain stage was possibly due to the translocation of $2 \mathrm{AP}$ from leaves to grains. At the mature grain stage, the amount of $2 \mathrm{AP}$ in rice leaves was significantly higher in the flag leaves, however, the amount of $2 \mathrm{AP}$ in leaves and seeds did not differ significantly. A consistent trend in 2AP variation in rice leaves was reported by Hinge, Patil and Nadaf (2016). The authors found that 2AP in leaves of fragrant rice, Ambemohar-157 (AM-157) and Basmati-370 (BA-370), increased from seedling stage to booting stage. They also found three times more 2AP accumulation in grains than in the leaves of seedlings. In contrast, KDML 105 rice showed no significant differences in 2AP content of the seeds at mature grain stage and leaves of seedlings. This could be due to many factors, such as the differences in rice variety, environment, and especially pre- and post-harvest treatment of the rice seeds.

At almost all growth stages, the accumulation of 2AP in seeds at the different branch positions showed no significant difference in the upper, middle, and basal branches. At the milk grain stage, the accumulation of $2 \mathrm{AP}$ in seeds at the basal branch corresponded to the significant increase in the 2AP content of panicle axis, likely due to the heighted activity of grain development at the reproduction stage. A decrease in 2AP content was observed in seeds at the soft dough grain stage. Furthermore, an increased in all seeds at the hard dough and mature grain stages was observed, where the 2AP content was highest in the seeds of the upper branches. There was a steady decline in the $2 \mathrm{AP}$ content of panicle axis and branches after the milk grain stage.

KDML 105 rice plants grown in sandy soil showed higher 2AP content than those in clay soil. These results were in agreement with the findings of previous studies (Sarvestani et al., 2008; Thanachit et al., 2014). Sandy soils have a lower water holding capacity and higher cation exchange capacity of minerals in the soil and root system. Minerals such as $\mathrm{N}$ and $\mathrm{P}$ are said to increase photosynthesis and tillering, consequently increasing rice yield by increasing panicles and grains. Potassium is involved in the regulation of osmotic potential linked to the reduction 
of diseases as well as boosted root development in rice plants, whilst calcium is believed to impact straw stiffness, seed, and grain formation (Kushwaha, 2016).

Rice plants treated with $\mathrm{Mg}$ had the highest $2 \mathrm{AP}$ content at tillering, followed by $\mathrm{Mn}$. In rice plants $\mathrm{Mg}$ is a component of chlorophyll and is involved in the translocation of other minerals. At tillering, $\mathrm{Mg}$ is taken up in higher concentrations than most other minerals and acts as an enzymatic activator (Marschner, 2012). The presence of $\mathrm{Mg}$ in rice plants is linked to high yield due to its involvement in chlorophyll synthesis. However, $\mathrm{Mg}$ showed no effect on 2AP content in rice leaves in other growth stages whilst Mn increased the 2AP content in all four stages of rice plant development.

At booting stage, $\mathrm{Cu}$ and $\mathrm{Cr}$ highly promoted $2 \mathrm{AP}$ formation, and the $2 \mathrm{AP}$ content was twice as high as that at the tillering stage. $\mathrm{Cu}$ is necessary at the seedling stage as it stimulates the absorption of water and nutrients from the soil (Kushwaha, 2016). The first report of Cr involvement in 2AP content is described in our study. Previous reports have suggested the association of $\mathrm{Cr}$ with the root systems of similar cereal plants, such as oats and corn, but according to our knowledge, its exact consequence on rice has not yet been studied (Samantaray, Rout, \& Das, 1998). The role of $\mathrm{Cr}$ on $2 \mathrm{AP}$ production at booting stage suggested that it is an important mineral for the reproductive stage of rice plants as opposed to the vegetative or ripening stages.

At heading, the $2 \mathrm{AP}$ content in the leaves of rice plants treated with $\mathrm{Cu}, \mathrm{Cr}$, and $\mathrm{Mg}$, decreased while those treated with $\mathrm{B}, \mathrm{Se}$, and $\mathrm{Mn}$ increased significantly. B stimulated a very high production of $2 \mathrm{AP}$ at the heading stage, double the amount at the booting stage. At the mature grain stage, grains of plants treated with B and Se had the highest amount of 2AP. B is associated with carbohydrate chemistry as well as pollen germination, pollen grain development, and seed production (Fageria, 2014). The involvement of B in seed production and grain development could have stimulated rice seeds and leaves to accumulate more 2AP than other mineral-treated rice plants. In addition, Se mitigates stress in plants because of its ability to induce the synthesis of S and $\mathrm{N}$ compounds, in addition to stimulating the activity of antioxidant enzymes and metabolites (Mikkelsen \& Wan, 1990; Shalaby et al., 2017). In this study, the addition of Se helped to increase the 2AP content of rice leaves at heading and seeds at mature grain stage. This suggests $\mathrm{Se}$ as an important mineral for the ripening stages of rice plants.

In summary, our result showed that the addition of $\mathrm{Mg}$ resulted in an increase of 2AP content at the tillering stage, whilst other elements reduced 2AP content compared to that of the control. $\mathrm{Cu}$ showed importance at the booting stage whilst $\mathrm{B}$ at the heading stage. Although $\mathrm{Mn}$ addition did not produce plants with the highest amount of 2AP, its contribution was seen as significant through-out the cultivation period. Mn increased the 2AP content in all four stages of rice plant development. Overall, addition of B to rice plants significantly increased the $2 \mathrm{AP}$ content in the leaves and seeds of KDML 105 rice plants.

\section{Conclusions}

This study investigated the effect of some mineral elements on the 2AP content in KDML105 rice plants and yielded positive results in elucidating the accumulation and translocation characteristics of 2AP in rice plants. The 2AP content varied among rice leaves, not only in the different growth stages, but also in different positions of the rice plant at each growth stage. Sandy soil facilitated higher 2AP content than that of clay soil. B treatments showed the highest amount of detected 2AP in both seeds and leaves of KDML 105 rice plants. There was a positive correlation between the amount of 2AP detected in rice leaves at the heading stage and seeds at the mature grain stage. Accordingly, mineral elements that stimulated 2AP production in the leaves at heading stage, as B did, had the most effect on the amount of $2 \mathrm{AP}$ that was accumulated in the rice seeds.

\section{Acknowledgements}

The authors would like to convey their gratitude to the Functional Food Research Center for Well-being, and the Research Center on Chemistry for Development of Health Promoting Products from Northern Resources, Chiang Mai University, and the Center of Excellence for Innovation in Chemistry (PERCH-CIC), Office of the Higher Education Commission, Ministry of Education, Thailand for their financial support through-out the entirety of this research. The authors would like to thank the Chiang Mai Rice Research Center, Sanpatong, for their facilities during the cultivation period.

\section{References}

Boontakham, P., Sookwong, P., Jongkaewwattana, S., Wangtueai, S., \& Mahatheeranont, S. (2019). Comparison of grain yield and 2-acetyl-1-pyrroline (2AP) content in leaves and grain of two Thai fragrant rice cultivars cultivated at greenhouse and open-air conditions. Australian Journal of Crop Science, 13(1), 159-169. https://doi.org/10.21475/ajcs.19.13.01.p1431 
Fageria, N. K. (2014). Mineral Nutrients of Rice. Florida: Taylor \& Francis Group. https://doi.org/10.1201/ b15392

Funsueb, S., Krongchai, C., Mahatheeranont, S., \& Kittiwachana, S. (2016). Prediction of 2-acetyl-1-pyrroline content in grains of Thai Jasmine rice based on planting condition, plant growth and yield component data using chemometrics. Chemometrics and Intelligent Laboratory Systems, 156, 203-210. https://doi.org/ 10.1016/j.chemolab.2016.06.008

Gay, F., Maraval, I., Roques, S., Gunata, Z., Boulanger, R., Audebert, A., \& Mestres, C. (2010). Effect of salinity on yield and 2-acetyl-1-pyrroline content in the grains of three fragrant rice cultivars (Oryza sativa L.) in Camargue (France). Field Crops Research, 117(1), 154-160. https://doi.org/10.1016/j.fcr.2010.02.008

Hänsch, R., \& Mendel, R. (2009). Physiological functions of mineral micronutrients (Cu, Zn, Mn, Fe, Ni, Mo, B and Cl). Current Opinion in Plant Biology, 12(3), 259-266. https://doi.org/10.1016/j.pbi.2009.05.006

Hinge, V., Patil, H., \& Nadaf, A. (2016). Aroma volatile analyses and 2AP characterization at various developmental stages in Basmati and Non-Basmati scented rice (Oryza sativa L.) cultivars. Rice, 9(1), 38. https://doi.org/10.1186/s12284-016-0113-6

Ishimaru, T., Nakayama, Y., Aoki, N., Ohsumi, A., Suzuki, K., Umemoto, T., ... Kondo, M. (2018). High temperature and low solar radiation during ripening differentially affect the composition of milky-white grains in rice (Oryza sativa L.). Plant Production Science, 21(4), 370-379. https://doi.org/10.1080/13439 43X.2018.1520047

Jones, J. (2014). Complete Guide for Growing Plants Hydroponically, Florida: Taylor \& Francis Group. https://doi.org/10.1201/b16482

Kong-ngern, K., Buaphan, T., Tulaphitak, D., Phuvongpha, N., Wongpakonkul, S., \& Threerakulpisut, P. (2011). Yield, Yield Components, Soil Minerals and Aroma of KDML 105 Rice in Tungkularonghai, Roi-Et, Thailand. International Journal of Agricultural and Biological Engineering, 5(4), 204-209.

Kushwaha, U. (2016). Black rice, Research, History, Development. New York: Springer International Publishing. https://doi.org/10.1007/978-3-319-30153-2

Lutts, S., Kinet, J., \& Bouharmont, J. (1996). Effects of salt stress on growth, mineral nutrition and proline accumulation in relation to osmotic adjustment in rice (Oryza sativa L.) cultivars differing in salinity resistance. Plant Growth Regulation, 19(3), 207-218. https://doi.org/10.1007/BF00037793

Marschner, P. (2012). Marschner's Mineral Nutrition of Higher Plants. Amsterdam: Elsevier/Academic.

Mikkelsen, R., \& Wan, H. (1990). The effect of selenium on sulfur uptake by barley and rice. Plant and Soil, 121(1), 151-153. https://doi.org/10.1007/BF00013109

Mo, Z., Huang, J., Xiao, D., Ashraf, U., Duan, M., Pan, S., ... Tang, X. R. (2016). Supplementation of 2-AP, Zn and La improves 2-acetyl-1-pyrroline concentrations in detached aromatic rice panicles in vitro. PloS One, 11, e0149523. https://doi.org/10.1371/journal.pone.0149523

Pitiphunpong, S., \& Suwannaporn, P. (2009). Physicochemical properties of KDML 105 rice cultivar from different cultivated locations in Thailand. Journal of the Science of Food and Agriculture, 89(13), 2186-2190. https://doi.org/10.1002/jsfa.3701

Samantaray, S., Rout, G., \& Das, P. (1998). Role of chromium on plant growth and metabolism. Acta Physiologiae Plantarum, 20(2), 201-212. https://doi.org/10.1007/s11738-998-0015-3

Sarvestani, Z. T., Pirdashti, H., Sanavy, S. A., \& Balouchi, H. (2008). Study of water stress effects in different growth stages on yield and yield components of different rice (Oryza sativa L.) cultivars. Journal of Biological Sciences, 11(10), 1303-1309. https://doi.org/10.3923/pjbs.2008.1303.1309

Schwarz, M. (1995). Soilless culture management. Berlin: Springer. https://doi.org/10.1007/978-3-642-79093-5

Shalaby, T., Bayoumi, Y., Alshaal, T., Elhawat, N., Sztrik, A., \& El-Ramady, H. (2017). Selenium fortification induces growth, antioxidant activity, yield and nutritional quality of lettuce in salt-affected soil using foliar and soil applications. Plant and Soil, 421(1-2), 245-258. https://doi.org/10.1007/s11104-017-3458-8

Singh, R., Singh, U., \& Khush, G. (2000). Aromatic rice. Enfield, N.H.: Science Publishers.

Tang, X. R., \& Wu, M. (2006). Effects of application of Zinc, Iron and Lanthanum on contents of aroma in brown rice and proline in flag leaf of aromatic rice. Hybrid Rice, 21, 69-72. 
Thanachit, S., Jedrum, S., Anusontpor, S., \& Wiriyakitn, W. (2014). Soil Amendments Effect on Yield and Quality of Jasmine Rice Grown on Typic Natraqualfs, Northeast Thailand. International Journal of Soil Science, 9(2), 37-54. https://doi.org/10.3923/ijss.2014.37.54

Xiao, D., Huang, J., Duan, M., Zhong, K., Li, G., \& Tang, X. (2010). Effects of different applications of $\mathrm{LaCl}_{3}$ on yield and aroma contents of aromatic rice. Journal of South China Agricultural University, 31(1), 115-116.

Xie, Z., Zhu, J., Chu, H., Zhang, Y., Gao, R., Zeng, Q., \& Cao, Z. H. (2004). Effect of lanthanum on rice growth and physiological parameters with split-root nutrient solution culture. Journal of Rare Earths, 21(1), 86-91.

Zeng, Y., Shen, S., Wang, L., Liu, J., Pu, X., Du, J., \& Qiu, M. (2005). Correlation of Plant Morphological and Grain Quality Traits with Mineral Element Contents in Yunnan Rice. Rice Science, 12(2), 101-106.

\section{Copyrights}

Copyright for this article is retained by the author(s), with first publication rights granted to the journal.

This is an open-access article distributed under the terms and conditions of the Creative Commons Attribution license (http://creativecommons.org/licenses/by/4.0/). 